\title{
Bur open Doctors' willingness to give honest answers about end-of-life practices: a cross-sectional study
}

\author{
Alan F Merry, ${ }^{1,2}$ Magdi Moharib, ${ }^{1}$ Daniel A Devcich, ${ }^{1}$ M Louise Webster, ${ }^{3}$ \\ Jonathan Ives, ${ }^{4}$ Heather Draper ${ }^{4}$
}

To cite: Merry AF,

Moharib M, Devcich DA, et al. Doctors' willingness to give honest answers about end-of-life practices: a crosssectional study. BMJ Open 2013;3:e002598.

doi:10.1136/bmjopen-2013002598

- Prepublication history and additional material for this paper are available online. To view these files please visit the journal online (http://dx.doi.org/10.1136/ bmjopen-2013-002598).

Received 16 January 2013 Revised 21 April 2013 Accepted 22 April 2013

This final article is available for use under the terms of the Creative Commons Attribution Non-Commercial 2.0 Licence; see http://bmjopen.bmj.com

\footnotetext{
${ }^{1}$ Department of Anaesthesiology, The University of Auckland, Auckland, New Zealand ${ }^{2}$ Auckland City Hospital, Auckland, New Zealand ${ }^{3}$ Starship Children's Hospital, Auckland, New Zealand ${ }^{4}$ Medicine, Ethics, Society and History, The University of Birmingham, Birmingham, UK
}

Correspondence to Professor Alan F Merry; a.merry@auckland.ac.nz

\begin{abstract}
Objectives: We aimed to (1) evaluate the extent to which doctors in New Zealand would be willing to answer honestly questions about their care of patients at the end of their lives and (2) identify the assurances that would encourage this. Results were compared with findings from a previous pilot study from the UK.
\end{abstract}

Design: Survey study involving a mailed questionnaire.

Setting: New Zealand hospital and community-based medical care settings.

Participants: The questionnaire was mailed to a random sample of 800 doctors in New Zealand who were vocationally registered with the Medical Council of New Zealand in disciplines involving caring for patients at the end of their lives.

\section{Primary and secondary outcome measures:}

Willingness to provide honest answers about various aspects of end-of-life care; assurances that might increase willingness to provide honest answers to questions about end-of-life practices.

Results: Completed questionnaires were returned by 436 doctors. The majority of respondents (59.9-91.5\%) indicated willingness to provide honest answers to such questions. However, more than a third of doctors were unwilling to give honest answers to certain questions regarding euthanasia. These results are comparable with the UK data. Complete anonymity was the assurance most likely to encourage honest answering, with most of the respondents preferring the use of anonymous written replies. Respondents were less reassured by survey endorsements from regulatory bodies. Themes in free comments included the deterrent effect of medicolegal consequences, fear of censure from society, peers and the media and concerns about the motivations and potential uses of such research.

Conclusions: Many New Zealand doctors were willing to give honest answers to questions about end-of-life practices, particularly if anonymity was guaranteed; others, however, expressed doubts or indicated that they would not be willing to provide honest answers to questions of this sort.

\section{ARTICLE SUMMARY}

Article focus

- Anecdotal and survey-based evidence strongly suggests certain end-of-life practices (ie, euthanasia and assisted suicide) occur, even in countries where they are illegal (eg, New Zealand and the UK).

- It is, however, unclear how willing doctors would be to answer honestly in any systematic attempt to capture the prevalence of illegal or potentially illegal end-of-life practices of this kind, as disclosure of such practices has the potential to lead to prosecution.

- This study evaluated the extent to which doctors in New Zealand would be willing to provide honest answers to questions about their care of patients at the end of their lives.

Key messages

- At least a third of doctors in New Zealand may not be willing to provide honest answers to questions explicitly addressing euthanasia and assisted suicide-results that support similar findings from the UK.

- Some New Zealand doctors are concerned about medicolegal risks and the possibility of censure from peers and society arising from research of this kind.

- The assurances most likely to be effective in encouraging honest reporting if surveyed include total anonymity and independence from regulatory bodies.

Strengths and limitations of this study

- The findings add to the body of knowledge on end-of-life research practice and provide some guidance for pursuing research in this area.

- The study is limited by systematic differences that may exist between respondents taking part in the survey and other doctors in New Zealand or other countries.

- Generalisability to other countries is limited by the different laws in different jurisdictions governing legal practice at the end of life, which may make it more or less difficult for doctors to report their practice honestly. 


\section{INTRODUCTION}

End-of-life practices including euthanasia ('death that results from the intention of one person to kill another person, using the most gentle and painless means possible, that is motivated solely by the best interests of the person who dies') ${ }^{1}$ and physician-assisted suicide (in which the means for patients to kill themselves is provided by physicians) have been the focus of much historical and ongoing social, ethical and legal debate. ${ }^{23}$ Euthanasia is illegal in many countries, including New Zealand, ${ }^{4}$ and various medical organisations (eg, the New Zealand Medical Association $)^{5}$ consider euthanasia and physician-assisted suicide unethical, irrespective of legality (in the UK, the General Medical Council has not taken a position on this matter, stating only that doctors should abide by the law). ${ }^{6}$ On the other hand, there are countries-notably the Netherlands-in which these practices are legal, ${ }^{7}$ and elsewhere there are those who advocate strongly for euthanasia and physician-assisted suicide. ${ }^{8}{ }^{9}$ The participation of lay media and politicians in the debate can be provocative, ${ }^{10}$ but research suggests that there may be an increasing social acceptance of euthanasia and physician-assisted suicide in many Western countries, ${ }^{11}{ }^{12}$ a perspective particularly evident among certain secular and sociodemographic sectors. ${ }^{11} 13$

It follows that there would be value in increasing our understanding of the factors contributing to decisions at the end of life, the extent to which euthanasia and physician-assisted suicide actually occur, and the context and conditions under which they occur. For example, the European End-of-Life Decisions (EURELD) Consortium has attempted to gauge doctors' attitudes towards end-of-life practices to identify factors influencing their decisions and experiences across a selection of predominantly European countries. ${ }^{14-16}$ In many European countries, however, euthanasia is illegal, and doctors participating in this research risk prosecution if they disclose their part in illegal practices. This raises the question of how willing the doctors would be to provide honest answers about their end-of-life practices. The answer to this question has significant implications for the trustworthiness of studies ${ }^{17}$ that report doctors' practices in this context. A pilot study conducted in the UK by Draper $e t a l^{18}$ investigated these questions, and this paper reports a larger study conducted in New Zealand using the same questionnaire.

This study had two primary aims (1) to evaluate the extent to which doctors in New Zealand would be willing to answer honestly questions about their practices and clinical decisions at the end of life and (2) to identify assurances that would encourage doctors to provide honest answers. We were also interested in comparing our results with those of the UK pilot study.

\section{METHODS}

\section{Study design and questionnaire}

A descriptive approach was used involving the collection of quantitative and qualitative survey data. A questionnaire (see appendix) was mailed to a random sample of practising doctors in New Zealand from a range of disciplines. The questionnaire, originally piloted in the UK, ${ }^{18}$ explored the participants' willingness to provide honest answers to specific end-of-life practices. The aim of the questionnaire was not to gain insight into the actual practices of participants (unlike the EURELD questionnaire studies), but to lay the foundation for research of this kind by gauging the level of willingness to answer end-of-life care questionnaires honestly in the first place. Accordingly, the questions were designed to include the descriptions of some practices that are currently illegal in both the UK and New Zealand, and others which are on the potentially fluid border of legality, the assumption being that there is greater risk of doctors not willing to provide honest answers to illegal or questionably legal practices.

The questions covered situations relating to either withholding or withdrawing medical treatment, prescribing medication, or alleviating pain and suffering and the influence of the patient's underlying condition. The questionnaire also asked participants to select from a list of assurances those that would encourage honest answers to questions about end-of-life practices. Examples of assurances included the possibility of using written replies, using anonymous internet surveys, and endorsement from medical organisations, such as the Medical Council of New Zealand or the Ministry of Health. Two open-ended questions were also included in the questionnaire: (1) "Why do you think that you, or other doctors, would not be prepared to answer questions such as those above honestly?" and (2) "Are there any other reassurances you would require?" Other data collected included respondents' discipline (eg, general practice, neurosurgery and palliative medicine), grade (eg, vocationally registered and registrar), sex and whether they were a practising member of a faith group. In addition, doctors not wishing to participate in the study were invited to provide a reason for this from a short list of alternatives.

\section{Procedure and participants}

The study targeted doctors who were thought likely to (1) have regular contact with dying patients and (2) be in a position to make authoritative decisions at the end of life. Following ethics committee approval, we selected a random sample of 800 eligible participants drawn from a list of doctors registered with the Medical Council of New Zealand in 2006 under the following disciplines: anaesthesia, general practice, internal medicine, obstetrics and gynaecology, paediatrics, palliative medicine and various subspecialities of surgery. To protect the anonymity of respondents, non-identifiable questionnaires were posted with a generic prepaid return envelope. Consent to take part in the study was taken as given by the return of a completed questionnaire, unless this indicated unwillingness to participate. 


\section{Analysis of data}

Descriptive statistics (absolute numbers and percentages) were used to summarise the responses. Following the method used in Draper et als pilot study, ${ }^{18}$ we calculated an 'honesty score' (ranging from -15 to 18 ) for each respondent to measure consistency in willingness to provide honest answers. Scoring was weighted to take into account the risk associated with the reporting of some end-of-life practices: high positive scores were assigned to responses indicating a willingness to provide honest answers to potentially high-risk questions, where honesty could have serious legal or professional consequences; high negative scores, on the other hand, were assigned to responses indicating a lack of willingness to provide honest answers to the lowest risk questions, where an honest answer would be unlikely to have legal or professional consequences (see table 1). Differences that emerged between groups were tested using non-parametric statistical tests. A basic content analysis approach was taken for open-ended questions: one author (DAD) identified emergent categories by examining the dataset and coding the responses. Categories were then reviewed by another author (AFM), who then independently coded a random sample $(20 \%)$ of the dataset. Intercoder reliability statistics were then calculated and frequencies of themes were summarised. Examples of responses were used to supplement and illustrate the findings.

\section{RESULTS}

Of the 800 surveys sent out, $590(73.8 \%)$ were returned; however, 91 of these noted unwillingness to take part, with around three-quarters of these responses indicating that respondents were too busy, and the rest, in approximately equal proportions, indicating either mistrust or lack of interest in the research. In accordance with the pilot study conducted by Draper et $a l^{18}$ incomplete questionnaires were excluded $(n=63)$, yielding a total of $436(54.5 \%) \mathrm{com}-$ pleted questionnaires for analysis. Most respondents were male $(70.4 \%)$, and most did not identify as a practising member of a faith group $(67.9 \%)$. Approximately half $(50.9 \%)$ were in general practice, a proportion consistent with 2006 New Zealand medical workforce statistics. ${ }^{19}$

A high proportion of respondents indicated that they would answer honestly, to varying degrees, each question about end-of-life practices (see table 2). A comparison of questions 1 and 2 (table 2) indicates that slightly more respondents felt that they would answer honestly questions regarding withdrawing treatment than questions about prescribing drugs, even though the intention in each case was to hasten death (McNemar test, $\mathrm{p}<0.001)$. For the remaining questions, the implicit intent of each action asked about (and therefore its potential legal and professional consequences) seemed to dictate the proportion of respondents willing to provide honest answers about end-of-life practices: the two lowest rates of willingness to provide honest answers were for questions 5 and 8 , about actions with the intention of hastening death (ie, explicitly about euthanasia); conversely, more respondents felt they would be willing to provide honest answers about essentially identical actions where the possibility of hastening death was taken into account, but where there was no intention to hasten death (questions 3 and 6).

\section{Table 1 Calculation of the 'honesty score'}

\section{Question about end-of-life practices}

If the following questions were in a legitimate survey, would you answer honestly?

1. Can you recall causing the death of a patient by the use of a drug prescribed, supplied or administered by you with the explicit intention of hastening the end of that patient's life?

2. Can you recall causing the death of a patient by withdrawing treatment with the explicit intention of hastening the end of that patient's life?

Willing to give an honest answer

Yes No

$\begin{array}{ll}3 & -1 \\ 3 & -2\end{array}$

With reference to the death of a specific patient (ie, named patient), did you withhold or withdraw treatment:

3. Taking into account the possibility that this would hasten the patient's death?

4. Partly to hasten the patient's death?

5. With the explicit intention of hastening the patient's death?
$1-3$

$2-2$

$3-1$

With reference to the death of a specific patient (ie, named patient), did you intensify the alleviation of pain and suffering:

6. Taking into account the possibility that this would hasten the patient's death?

7. Partly to hasten the patient's death?

8. With the explicit intention of hastening the patient's death?

Points are allocated according to the potential riskiness of providing an honest answer to each question. Thus, for example, willingness to answer question 1 honestly is scored highly because it could possibly lead to prosecution, and unwillingness is not highly penalised because reluctance to take such a risk is understandable.

The honesty scores are not intended to show relative difference nor provide any indication of the absolute likelihood of answering honestly or dishonestly. 
Table 2 Number and percentage of respondents indicating they would be willing to answer honestly for each question about end-of-life practices

\begin{tabular}{lcc}
\hline Would you answer honestly questions asking if you had: & Yes & Per cent \\
\hline (1) Prescribed drugs (for supply or administration) with intention to hasten death? & 351 & 30.5 \\
(2) Withdrawn treatment with intention to hasten death? & 382 & 388 \\
(3) Withheld or withdrawn treatment taking into account possibility of hastening death? & 337 & 87.6 \\
(4) Withheld or withdrawn treatment partly to hasten death? & 271 \\
(5) Withheld or withdrawn treatment with the intention of hastening death? & 399 \\
(6) Alleviated pain and suffering taking into account the possibility of hastening death? & 316 \\
(7) Alleviated pain and suffering partly to hasten death? & 261 \\
(8) Alleviated pain and suffering with the intention of hastening death? & 92.2 \\
\hline
\end{tabular}

The New Zealand responses were essentially comparable with those from UK doctors to the same questions about end-of-life practices. The considerable majority of both groups indicated that they would answer all the questions honestly, and the overall pattern of response was quite similar in each group (see figure 1).

The New Zealand data show that respondents were evenly divided regarding the influence that patient factors would have on decisions to provide an honest answer about end-of-life practices: approximately half $(48.6 \%)$ of the respondents indicated that the patient's status in respect to being terminally ill would influence their willingness to provide honest answers to questions about end-of-life practices, and similarly around half $(51.1 \%)$ also indicated the influence of whether or not the patient-or family-had discussed their views with them. A minority (36.5\%) of respondents, however, felt that the patient's level of competence would be a factor informing their willingness to provide honest answers.

The 'honesty score' data are presented in table 3. Over three-quarters $(77.5 \%)$ of respondents indicated that they would consistently provide honest answers to questions on end-of-life practices, and about half $(51.1 \%)$ scored the maximum of 18-implying that

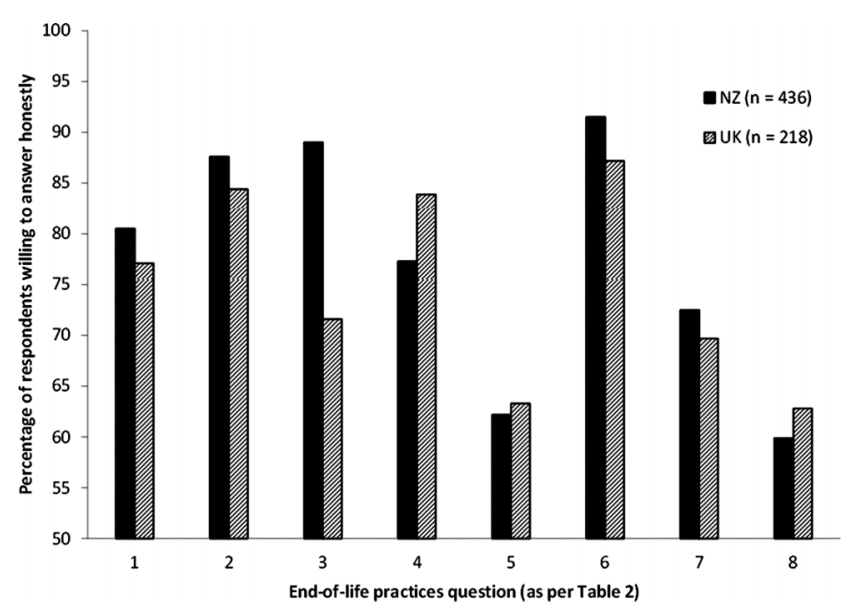

Figure 1 Comparison of percentage of respondents in New Zealand and the UK who would be willing to provide honest responses to questions about end-of-life practices. every question about end-of-life practices would be met with an honest answer. 'Honesty scores' seemed to be different between general practitioners (GPs) and doctors from other specialties (Mann-Whitney $U$ test, $\mathrm{p}=0.006$ ), with GPs indicating less willingness to provide consistently honest answers (median=14) than non-GPs (median=18). This pattern seemed to be most evident in questions relating to situations where treatment is withdrawn or withheld (questions 2-5 of table 2) with GPs less willing to provide honest answers to such questions than non-GPs $\left(\chi^{2}\right.$ tests, all $\left.\mathrm{p}<0.05\right)$.

Respondents were asked to identify assurances that might increase their willingness to provide honest answers to questions about end-of-life practices (see table 4). Two items were identified as important by most respondents: the use of anonymous written replies $(n=346 ; 79.4 \%)$ and reassurance that the research

Table 3 Distribution of honesty scores

\begin{tabular}{|c|c|c|c|}
\hline Honesty score & $\mathbf{N}$ & Per cent & Cumulative (\%) \\
\hline \multicolumn{2}{|c|}{$\begin{array}{l}\text { Consistently unwilling to } \\
\text { provide honest answers }\end{array}$} & (10.6) & \\
\hline-15 & 13 & 3.0 & 3.0 \\
\hline-11 & 9 & 2.1 & 5.0 \\
\hline-7 & 13 & 3.0 & 8.0 \\
\hline-6 & 11 & 2.5 & 10.6 \\
\hline \multicolumn{2}{|c|}{$\begin{array}{l}\text { Neither consistently } \\
\text { willing nor unwilling to } \\
\text { provide honest answers }\end{array}$} & (11.9) & \\
\hline-3 & 4 & 0.9 & 11.5 \\
\hline-2 & 20 & 4.6 & 16.1 \\
\hline 1 & 3 & 0.7 & 16.7 \\
\hline 2 & 25 & 5.7 & 22.5 \\
\hline \multicolumn{2}{|c|}{$\begin{array}{l}\text { Consistently willing to } \\
\text { provide honest answers }\end{array}$} & (77.5) & \\
\hline 5 & 3 & 0.7 & 23.2 \\
\hline 6 & 32 & 7.3 & 30.5 \\
\hline 9 & 8 & 1.8 & 32.3 \\
\hline 10 & 47 & 10.8 & 43.1 \\
\hline 13 & 1 & 0.2 & 43.3 \\
\hline 14 & 24 & 5.5 & 48.9 \\
\hline 18 & 223 & 51.1 & 100.0 \\
\hline Total & 436 & 100.0 & \\
\hline
\end{tabular}


Table 4 Number and percentage (ranked highest to lowest) of respondents indicating that the listed items (ie, assurances) might encourage them to respond honestly to research questions about end-of-life practices

\section{Assurances that might encourage honesty regarding end-of-life practices}

(1) The use of anonymous written replies

(2) Reassurance that the method made it absolutely impossible to link respondent identity with responses

(3) Signed undertaking by the researchers never to reveal the respondent identity

(4) Guarantee from government department, medical council, etc that the replies would never be used to investigate the practices of any individual respondent

(5) The use of interviews with a registered medical practitioner, with guarantee that the responses would be anonymous

(6) Promise from researchers to never divulge the link between the respondents and their replies, even if faced with prosecution

(7) Endorsement of survey from the Medical Council of New Zealand

(8) The use of an anonymous internet survey

(9) The use of interviews with the researcher, with guarantee that the responses would be anonymous

method made it absolutely impossible to link the identity of the respondents with their responses $(n=270$; $61.9 \%)$. Each of the remaining items was identified as important by less than half of the respondents. Some of the least reassuring items included endorsements from regulatory bodies, including the Medical Council of New Zealand $(n=123 ; 28.2 \%)$ and the Ministry of Health $(n=85 ; 19.5 \%)$, and the use of an anonymous internet survey $(n=117 ; 26.8 \%)$. Respondents were also asked to indicate which of the assurances might prove to be decisive in promoting honest reporting of end-of-life practices. Again, items 1 (the use of anonymous written replies) and 2 (reassurance that the method made it absolutely impossible to link respondent identity with responses) from table 4 were frequently identified by respondents, as was item 4 (guarantee from government department, medical council and the like that the replies would never be used to investigate the practices of any individual respondent).

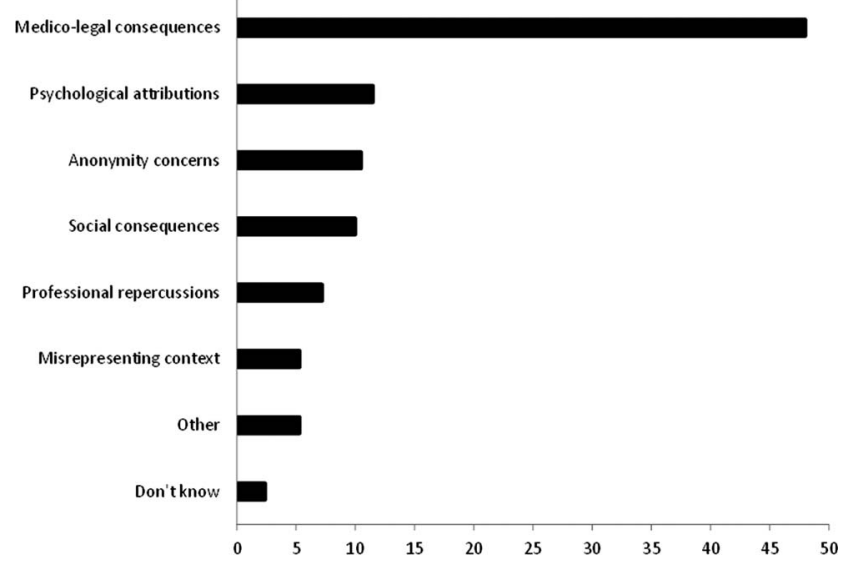

Figure 2 Major reasons (as a percentage of all coded comments) cited by respondents to explain doctors' reluctance in reporting end-of-life practices honestly.
For the two open-ended questions, there was substantial agreement between coders: $\kappa$ coefficients were 0.79 $(p<0.05)$ for the first question and $0.72(p<0.05)$ for the second. ${ }^{20}$ The first open-ended question invited respondents to comment on what they thought the reasons were that they (or other doctors) would not be prepared to answer honestly questions about end-of-life practices (see figure 2). Over three-quarters $(77.3 \%)$ of respondents made comments, with most citing possible medicolegal consequences as a major deterrent (48\%). Other reasons were cited much less often (ranging from $11.5 \%$ for psychological attributions to $5.3 \%$ for misrepresenting context). Some of the suggested reasons related to social consequences and psychological attributions: social consequences included fears of censure and judgement from society, peers and the media, with some respondents raising the possibility of negative publicity and public ostracism as deterrents to honest reporting of end-of-life practices; psychological attributions used to explain reluctance in reporting honestly included feelings of guilt, lack of self-honesty or reflective practice and difficulties posed by holding conflicting beliefs or ideals (eg, 'cognitive dissonance-conflict of what we believe and what we actually do'). Other reasons included threats to anonymity ('If they (were) anonymised I can't see a problem') and potential professional repercussions (eg, being investigated by the Medical Council of New Zealand or the Health and Disability Commissioner and perhaps being struck off the medical register). Some respondents also identified concerns that reporting may not encapsulate the full context of the action or the decision behind it (such decisions are by no means black and white). Others indicated that doctors may not wish to report honestly because of concerns about patient confidentiality or the need to 'protect the family of the person whose death was facilitated.' Other reasons cited included mistrust in the motives and agendas of those collecting the data 
('Statistics could be used against [the] medical profession') and the dilemmas some may feel about engaging in a sensitive and murky issue ('The reality that doctors do withdraw treatment may be seen by some as admitting to 'wrong' doing'). A few respondents thought that most doctors probably would answer honestly; some did not offer a reason for reluctance to report end-of-life practices honestly.

Fewer respondents $(112 ; 25.7 \%)$ provided comments on the second open-ended question, regarding any other assurances that would be required to encourage honesty in reporting end-of-life practices. Many respondents communicated the need for complete anonymity (eg, 'Anonymity would be the only acceptable way-as soon as it becomes face to face honesty may be lost'). An almost equal proportion, however, did not take comfort from any of the listed assurances:

I would be concerned with any of these that it could backfire. Internet can be hacked. Researchers could be obliged to divulge information. The risks are too great, albeit exceptionally unlikely that there would be comeback.

Some respondents indicated that they would answer honestly in any case, either as a matter of principle or as a reflection of their compliance with the law:

I don't need any inducement to answer honestly nor am I afraid of divulging my practice.

I would always answer honestly, as I hope I will always be able to defend my practice as being within the law. Reassurances are irrelevant.

Respondents in a number cases communicated skepticism about the extent to which medical and government organisations could be trusted; similarly, although some respondents raised the importance of guarantees against prosecution, more were skeptical about the perpetuity of guarantees and promises against identification, investigation and prosecution. Other potential assurances included publication of data in peer-reviewed journals only and the destruction of any data linking respondents with their responses.

A few additional comments reflected some of the difficulties faced by doctors when making decisions about end-of-life practices. The following comments reflect the ethical tightrope that doctors may walk to act within (albeit close to) the boundaries of the law on the one hand and compassionately consider their patients' desires and best interests on the other:

I would not say that withdrawing treatment is/was intended to hasten the end of a patient's life, but rather not to prolong it to reduce suffering. Some would not answer the questions above honestly as there is a very fine line between compassion and caring and negligent and illegal behaviour.
In this instance it is better that there [is] a difference between occasional practice and the law. Very occasionally for the sake of an individual patient it may be better to be dishonest to society at large.

Without an honest answer there can be no 'honest' result. Unfortunately, what we are taught to do as medical practitioners and what we personally believe are often at conflict.

\section{DISCUSSION}

Most doctors taking part in the survey indicated that, in general, they would be willing to provide honest answers to questions about practices in caring for patients at the end of their lives: over three-quarters of respondents indicated they would be consistently willing to provide honest answers to a range of questions on end-of-life practices. Willingness was higher for questions where the potential risks were likely to be lower, but in situations explicitly involving euthanasia or physician-assisted suicide, somewhere between a third and half of respondents would not be willing to report honestly (table 2). There also seemed to be a modest difference between responses to question 2 (table 2) about withdrawing treatment with the explicit intention of hastening death and question 1 about actively prescribing drugs with the same intention, presumably reflecting the distinction that is often made between acts and omissions, even though the law in New Zealand makes no such distinction where the intention is to hasten death. ${ }^{21}$ In questions $3-5$ and $6-8$, the willingness to provide honest answers decreased as references to the intention to hasten death became more explicit, presumably reflecting an increased risk that the latter actions would be regarded as illegal if investigated.

The pattern of responses to questions in the present study was essentially similar to responses from the previous pilot study that sampled registered doctors from the $\mathrm{UK}^{18}$ This pattern was evident when comparing responses to questions about end-of-life practices and also with regard to the 'honesty score' data-the percentage of UK doctors consistently willing to provide honest answers was $72 \%$ (compared with our study's $77.5 \%$ ), and the proportion scoring the maximum was approximately half in each case ( $52.3 \%$ vs $51.1 \%$ in our study).

An observation that emerged from our data was that GPs may be more cautious in their reporting of end-of-life practices than hospital specialists: GPs scored less on the overall 'honesty score' (ie, they were less consistently willing to provide honest answers) and in particular were less likely than hospital specialists to provide honest answers to questions about end-of-life practices involving the withdrawal or withholding of treatment. Our findings align with those of Minogue et $a l^{22}$ who showed that the perception of vulnerability to litigation looms high in the minds of some GPs and GP registrars in New Zealand. Such perceptions may plausibly result in more reticence in the reporting of end-of-life 
practices, although the finding, at its heart, may reflect notable differences between community-based medicine and hospital medicine, where hospital specialists are more likely to have the opportunity (eg, on ward rounds) to discuss the proposed management of such patients with colleagues, perhaps leading to a greater sense that they have the moral support of colleagues. In addition, the nature of responsibilities associated with general practice and the long-term relationships developed between GPs and many of their patients may mean that simple questions about end-of-life practices are seen as failing to fully encapsulate the context in which decisions are made. A number of responses to the openended questions in our study support this point. This suggests that research investigating GPs' (and indeed any doctors') end-of-life practices should probably aim to address more fully the context, nuances and complexities of their particular field of clinical practice.

Every effort should also be made to provide those assurances that are likely to encourage honest answers: anonymity seems to be the most important of these, but the purposes of the research and the likely uses of the data also seem to matter. Again, these findings mirror responses from the UK doctors. ${ }^{18}$ Doctors were divided about the involvement of medical organisations (eg, the Medical Council of New Zealand) and government in the provision of reassurances: some saw guarantees against investigation or prosecution from such medical bodies as being decisive in encouraging honest reporting; others were skeptical of institutional involvement per se, and the concern that such promises carry little weight was frequently raised.

Our study has several limitations. This study, by design, focuses on doctors, not on their patients. It applies to doctors in New Zealand, not to doctors in other countries (and particularly not to countries in which euthanasia is legal). In some countries, notably the Netherlands, some of the legal nuances of intention reflected in our questionnaire would not apply, because the law is more permissive. Others, such as the UK, are essentially similar to New Zealand in their legal approach to euthanasia (ie, it is illegal), and the only defence for an action that arguably hastened or caused a patient's death would be that this had been unintended, the intention having been simply to alleviate pain and suffering (the so-called doctrine of double effect defence). Even so, there were clear similarities between the responses to our survey and those to Draper et $a r^{18}{ }^{18}$ UK-based pilot study. Our sample was taken randomly from all practising New Zealand doctors and was reasonably large (far larger than the UK study as a proportion of the population in question), but although response rate $(73.8 \%)$ was good and the rate of analysable responses $(54.5 \%)$ was acceptable for a sensitive topic ${ }^{23}$ and adequate for analysis, ${ }^{24}$ it is quite likely that there are systematic differences between the respondents with analysable answers and other doctors in New Zealand. To this point, some of the returned questionnaires indicated unwillingness to take part in the research because of mistrust in our motives, and, although we know nothing about the larger portion of doctors who did not reply at all, it is certainly plausible that many of them may have shared this distrust. On the other hand, research on end-of-life practices has indicated that non-responders may have less experience with patients who are terminally ill and have more ambiguous attitudes towards end-of-life practices. ${ }^{25}$

We wish to emphasise that our data provide no information on the honesty of our respondents in particular or of doctors in general. It should be self-evident that we also have no way of knowing whether the answers that were provided were honest, but it is equally true that there is no good reason to doubt this. More importantly, even those doctors who indicated unwillingness to provide honest answers to some of the questions or who declined to participate may well be scrupulously honest practitioners who were simply indicating, honestly (implicitly or explicitly), that they would not take part in such research at all. This, of course, is their prerogative. It is also possible that a willingness to be honest in respect to some or all areas of the survey reflected the confidence of these respondents that their own practice was actually legal (as suggested in some of the responses to the open questions). Our survey was not able to distinguish those who would reply honestly to a question about currently illegal practice because they do not engage in such practice and therefore an honest reply poses no risk to them. Similarly, we do not know how doctors who indicated that they would not be willing to give honest answers would actually respond to questionnaires about end-of-life practices: on the one hand, they may give dishonest responses (ie, report not having practised illegally when in fact they have); on the other hand, it is equally possible that they may not answer the questions at all. In addition, some general limitations of self-administered surveys should be kept in mind, ${ }^{26}$ particularly with regard to surveys of sensitive topics. ${ }^{27}$

Whatever be the views of a person with regard to this matter, the fact is that it is illegal to intentionally hasten the death of a patient in New Zealand, even at his or her explicit request and even in compassion. Nevertheless, there is evidence that such practices do occur in New Zealand. ${ }^{28}$ Our results suggest that it would be difficult to obtain a reliable quantitative picture of the extent to which patients' deaths are intentionally hastened in practice. On the other hand, they also suggest that a fairly good qualitative picture of practices, the concerns of doctors and matters needing to be addressed might well be obtained from carefully constructed questionnaires. We were encouraged that more than half of a large sample of New Zealand doctors were willing to provide analysable responses to a survey dealing (in a broad sense) with end-of-life practices and that the vast majority of these indicated willingness to give honest answers to questions about such practices, particularly if anonymity was guaranteed. Understandably, at least some New 
Zealand doctors expressed suspicion about the motivations and potential uses of such research, while others indicated that they would not be willing to provide honest answers to questions of this sort.

Our results support the principle that research of this type requires sensitivity and awareness of the concerns doctors may face about the sometimes very difficult decisions they are required to make when caring for patients who are seriously ill and facing death. They reinforce the importance of ensuring the total anonymity of the respondents. The purposes of any such survey and the intended use of the data are also relevant. It would seem best that research of this type should be conducted independently from regulatory bodies and attention should also be given to developing questions that take into account the wider context in which decisions are made by doctors in different clinical settings.

Understanding how to care for patients in the best way at the end of their lives is very important, and it is unfortunate that the legal and social context of medical practice in New Zealand (and many other countries) is likely to impede research in this field. Our findings are broadly similar to those of a pilot study in the UK and provide some guidance for those wishing to pursue research in this area, at least in New Zealand and probably elsewhere as well.

Acknowledgements We would like to thank Doctors Phillipa Malpas and Leona Wilson and Associate Professor Sally Merry for their helpful comments and feedback on the draft manuscript. We would also like to acknowledge Professor Sue Wilson and Doctors Stephen Smith and Hardev Pall for their input in the questionnaire design.

Contributors AFM conceived and oversaw the design of the New Zealand study, liaised with the UK investigators, oversaw the research and contributed substantially to writing the manuscript. MM contributed to the design of the NZ study and carried out the survey. DAD analysed the data and prepared the first draft of the manuscript. MLW contributed to the design of the New Zealand study. $\mathrm{JI}$ and $\mathrm{HD}$ provided input in the design of the questionnaire and study. All authors contributed to revising the manuscript.

Funding This research received no specific grant from any funding agency in the public, commercial or not-for-profit sectors.

Competing interests None.

Ethics approval Approval was obtained from the New Zealand Ministry of Health Multi-Region Ethics Committee (MEC/06/10/121).

Provenance and peer review Not commissioned; externally peer reviewed.

Data sharing statement No additional data are available.

\section{REFERENCES}

1. Draper H. Euthanasia. In: Chadwick R.ed Encyclopedia of applied ethics. San Diego: Academic Press, 1998:175-87.
2. Huxtable R, Campbell AV. Palliative care and the euthanasia debate: recent developments. Palliat Med 2003;17:94-6.

3. Huxtable R. Law, ethics and compromise at the limits of life: to treat or not to treat? Oxford: Routledge, 2012.

4. New Zealand Government. Crimes act 1961. Wellington: New Zealand Government, 2012.

5. New Zealand Medical Association. Position statement on euthanasia, 2005. http://www.nzma.org.nz/policies/advocacy/ position-statements/euthanasia

6. General Medical Council. Response to DPPs' consultation on assisted suicide, 2012. http://www.gmc-uk.org/guidance/5643.asp

7. Griffiths J, Weyers H, Adams M. Euthanasia and law in Europe. Oxford: Hart Publishing, 2008.

8. ABC News. Nitschke on euthanasia and consent, 2012. http://www. abc.net.au/news/2012-04-02/nitschke-on-euthanasia-and-consent/ 3927178

9. BBC News. Sick patients 'need right to die', 2008. http://news.bbc. co.uk/2/hi/uk_news/scotland/7507486.stm

10. The New Zealand Herald. PM's 'misguided' euthanasia views anger palliative care specialists, 2012. http://www.nzherald.co.nz/nz/news/ article.cfm?c_id=1\&objectid=10829058

11. Cohen J, Marcoux I, Bilsen J, et al. European public acceptance of euthanasia: socio-demographic and cultural factors associated with the acceptance of euthanasia in 33 European countries. Soc Sci Med 2006;63:743-56.

12. Allen J, Chavez S, DeSimone S, et al. Americans' attitudes toward Euthanasia and physician-assisted suicide, 1936-2002. J Sociol Soc Welf 2006;33:5-23.

13. Horizon Research. New Zealanders' views on end of life choices. Auckland, 2012. http://www.horizonpoll.co.nz/attachments/docs/ horizon-research-end-of-life-choices-survey-1.pdf

14. Van Der Heide A, Deliens L, Faisst K, et al. End-of-life decision-making in six European countries: descriptive study. Lancet 2003;362:345-50.

15. Onwuteaka-Philipsen BD, Fisher S, Cartwright C, et al. End-of-life decision making in Europe and Australia: a physician survey. Arch Intern Med 2006;166:921-9.

16. Löfmark R, Nilstun T, Cartwright C, et al. Physicians' experiences with end-of-life decision-making: survey in 6 European countries and Australia. BMC Med 2008;6:4. doi:10.1186/1741-7015-6-4.

17. Seale C. National survey of end-of-life decisions made by UK medical practitioners. Palliat Med 2006;20:3-10.

18. Draper $\mathrm{H}$, Ives J, Pall $\mathrm{H}$, et al. Reporting end-of-life practice: can we trust doctors to be honest? Palliat Med 2009;23:673-4.

19. Medical Council of New Zealand. The New Zealand medical workforce in 2006. Wellington: Medical Council of New Zealand, 2006.

20. Landis JR, Koch GG. The measurement of observer agreement for categorical data. Biometrics 1977;33:159-74.

21. Begley AM. Acts, omissions, intentions and motives: a philosophical examination of the moral distinction between killing and letting die. $J$ Adv Nurs 1998;28:865-73.

22. Minogue M, Goodyear-Smith F, Fishman T. The black hole of general practice manpower. NZFP 2005;32:317-22.

23. Sierles FS. How to do research with self-administered surveys. Acad Psychiatry 2003;27:104-13.

24. Babbie E. The practice of social research. 11th edn. Belmont, CA: Wadsworth, 2007

25. Fischer S, Miccinesi G, Hornung R, et al. Responders and non-responders in a study on medical end-of-life decisions in Denmark, the Netherlands, Sweden and Switzerland. Soz Praventivmed 2006;51:24-33.

26. Rubenfeld GD. Surveys: an introduction. Respir Care 2004:49:1181-5.

27. Tourangeau R, Yan T. Sensitive questions in surveys. Psychol Bull 2007;133:859-83.

28. Mitchell K, Owens RG. End of life decision-making by New Zealand general practitioners: a national survey. $N Z$ Med $J$ 2004;117:U934. 